\title{
A REPORT ON THE COURTSHIP BEHAVIOUR AND CAPTIVE BREEDING VIA ARTIFICIAL INCUBATION OF CHINESE SILVER PHEASANT (Lophura nycthemera)
}

\author{
T. CHATTERJEE ${ }^{1 *}$, R. MUKHERJEA² AND P. K. DAS ${ }^{3}$
}

\author{
${ }^{1}$ Zoological Garden, Alipore, Kolkata-700 027, West Bengal, India \\ ${ }^{2}$ Teaching Veterinary Clinical Complex, West Bengal University of Animal \& Fishery Sciences, \\ Kolkata-700 037, India \\ ${ }^{3}$ Department of Veterinary Physiology, West Bengal University of Animal \& Fishery Sciences, \\ Kolkata-700 037, India
}

\begin{abstract}
Captive breeding programme is one of the most important ex-situ conservation techniques that may help to maintain a steady population of species in the zoos. During captivity, it is often seen that in many cases of birds, they lay eggs but give up brooding. To resolve this problem, artificial incubation technique has been adopted. This communication reports detailed observation regarding courtship behaviour, mating as well as successful breeding of two chicks of Chinese Silver Pheasant at Zoological Garden, Alipore, Kolkata and their subsequent growth rate.
\end{abstract}

Key words: Artificial incubation, Brooder, Captive breeding, Courtship behaviour, Growth rate

Captive breeding of birds is an age-old practice in the human society for easy availability of food, preparing game birds for fun and enjoyment and lastly, using them as pets. But, with rapid loss of species worldwide, long-term maintenance of captive populations has become a common approach to species conservation (Heinrichs et al., 2019). Extinction rates are going up and it is predicted that $20-50 \%$ of the world's species will become extinct in the next couple of decades (Tollefson, 2019) and around a quarter of extant species are considered to be threatened with extinction (Croteau and Mott, 2011).

Presently, zoos act as somewhat of an "arc" by holding the world's species in captivity and saving their genetic material from total elimination. Now captive breeding programme in zoo are not only there to bring in a crowd, their main focus is to help conserve animals which are endangered or threatened in the world so that a species doesn't become extinct.

Birds belonging to family Phasianidae showed little spatial movement throughout the year. Almost all existing descriptions of their social behaviours were established in captive conditions (Deeming et al., 2011; Santilli and Bagliacca, 2017, 2019). Several studies had been conducted in respect of the courtship behaviour and sexual selection of socially polygynous species including Cabot's Tragopan (Tragopan caboti) (Botero and Rubenstein, 2012), Ring-necked Pheasant (Phasianus colchicus) (Hunt et al., 2009), Red Jungle fowl (Gallus gallus) (Tan et al., 2016).The present study documented the courtship behaviour

\footnotetext{
*Corresponding Author
} 
and mating pattern of Silver Pheasants (Lophura nycthemera) at Zoological Garden, Alipore, Kolkata. Information gained from this close observation helps to increase the success rate of breeding of the particular species in captivity.

During captivity, it is often seen that the animals do not breed at all and the fertility problems were related to the closely interwoven aspects of maintenance and behaviour (Comizzoli and Holt, 2019). Moreover, in many cases of birds and reptiles, they lay eggs but do not sit on them for natural incubation. In such cases zoos often adopt the technique of captive breeding via artificial incubation. Though the success rate is not high but the zoos always trying to breed animals in captive (Balmford et al., 2011). Recently, Zoological Garden, Alipore, Kolkata has successfully bred two Chinese Silver Pheasants, with the help of artificial incubation. As per available records, this happens for the first time in the history of this $146^{\text {th }}$ years old zoo in West Bengal.

\section{MATERIALS AND METHODS}

Study area: The Zoological Garden, Alipore, Kolkata is lying in between $22^{\circ} 32^{\prime} 9.29^{\prime \prime} \mathrm{N}$ latitude and $88^{\circ} 19^{\prime} 55.39^{\prime \prime}$ E longitude with an area of 18.81 ha (46.5 acres). The study was conducted at "Swarnomoyee House", which is precisely a bird enclosure of the zoo.

Study period: The study was conducted at the zoo from mid February to April, i.e. their breeding period during the two consecutive years 2017 and 2018.

Observation method: The entire study was conducted at "Swarnomoyee House", where 6 Silver Pheasants were kept in a ratio of $3 \mathrm{M}: 3 \mathrm{~F}$ in three separate enclosures and observations were conducted during 8:00-11:00 in the morning and 2:00-5:00 in the afternoon session of the day. Observers initially conducted preliminary observations by collecting notes on the birds' various behaviours, and sometimes videography was done wherever possible from inside of the cage.
In the year 2017, total seven eggs were laid by females. But they were reluctant to brood on that space, after continuous observation of twentyfour hours all the eggs were collected and placed into the incubator for artificial incubation.

\section{Hatching and rearing equipment}

Artificial incubator: For artificial incubation of the eggs, the study was conducted in Automatic Egg Incubators with 300 egg capacity manufactured by AP Poultry equipments.

Brooder: The baby chick brooder was made of aluminium shaving, and it was treated against insect attack. It was $60 \mathrm{~cm}$ in length, $30 \mathrm{~cm}$ in width and height, with a heating bulb fitted at the backside wall of each boxes. The bottom was installed with the netting mesh of $1.5 \mathrm{~cm}$ $x 1.5 \mathrm{~cm}$. Under the wire netting a faeces tray was installed. A feeding pot and a shallow water dish were put in each box.

In the year 2018, separate arrangements were executed for better privacy of hatching along with thatched nests looking like penthouse design and comfortable bedding arrangement of $10.16 \mathrm{~cm}$ (four inch) depth, filled with saw dust and chopped straw. After this cozy environment all the birds spent their time into the new place and laid their eggs comfortably. Total number of eggs collected from three females were nine, six and fourteen respectively.

Study method: Study method was reflected in the area of seasonal activity budget and various breeding behaviour. Seasonal activity budget was divided into two parts, as non breeding winter and breeding season. Both the division incorporated their daily activity of foraging, standing, sitting, locomotion and preening. The frequency of study of each activity was recorded in five minutes interval.

Various breeding behaviour includes mate guarding, male female lateral display, genus specific "wing whirring", courtship feeding and lastly with mating. 
Statistical analysis: The data recorded from the above mentioned study methods were assessed for their statistical significance. Student's t test was performed with the help of Past software ver 4.0.

Artificial incubation: The experiment was started with twenty four eggs which were collected in four days. These eggs were first stored in $4^{\circ} \mathrm{C}$ for about 4-5 days. After removal of eggs from cold storage, these were cleaned with lukewarm water to removed all the debris coupled with the egg shells. Sanitized all the eggs by chlorine solution (bleach, mild anticeptic). Composition of bleach is 1 gallon $(3.8 \mathrm{~L})$ of clean water mixed with 1 table spoon (15 mL of bleach) (Brander and Pugh, 1971). This is the routine practice used in Kolkata Zoo. Then these eggs and incubator were fumigated with $35 \mathrm{~mL}$ of $40 \%$ formaldehyde to $10 \mathrm{~g}$ of potassium permanganate per cubic meter of space for $20-25$ minutes. Eggs were set in the incubator at $36-38^{\circ} \mathrm{C}$ and $86 \%-88 \%$ humidity (Banerjee, 1998). After eight days of incubation candling was done to check fertility of the eggs. Reddish yolk and dark spots were seen in only three of the seven eggs. These three eggs were kept for further development, and the rest five eggs with pale yellow colour yolk were discarded. The eggs were then turned daily starting with the third day of incubation. During the early stages of incubation, the numbers of turns were restricted to five to six times daily, after about a week, the numbers of turnings were regulated at eight hours equal interval (Banerjee, 1998). After 14 days, during second phase of candling, the blood vessels were clearly visible in those three eggs.

Hatching of eggs: In our experiment, after 28 days, the eggs were hatched successfully and immediately the eggs were transferred to the hatcher tray after first crack in the egg shell was seen (Fig. 1). After a whole day, the first healthy chick came out completely outside the egg shell. Subsequently, the second chick came out of its shell successfully after another 13-14 hours.
Rearing temperature: The healthy chicks were kept in the brooder with suitable temperature and adequate amount of light. The temperature should be around $90^{\circ} \mathrm{F}\left(32.22^{\circ} \mathrm{C}\right)$ for the first week in the warmest part of the brooder and should be reduced by around $5^{\circ} \mathrm{F}$ each week thereafter, until the chicks have their feathers (5-8 weeks old). (Available in BackYardchickens.com). To maintain $30^{\circ}-35^{\circ} \mathrm{C}$ temperature inside the brooder, 100 watt bulb have been used throughout the first week and then gradually reduced it until the brooder temperature became same as ambient temperature (with the use of 100 watt -60 watt -50 watt -40 watt bulb) (Boleli et al., 2016) (Fig. 2).

Nutrition and feeding: On the first day, only glucose water was provided to the chicks orally. From the second day onwards, finely crushed rice grains along with glucose water was given to the chick. After one week, the available commercial poultry feed and water with suitable electrolytes was provided to the chicks. Vitamins A, D1, D3 were supplemented.

\section{RESULTS}

Seasonal activity budget: Graphical presentation depicted seasonal activity budget between the year 2017 and 2018. (Graph 2)

\section{Breeding behaviours:}

Mate Guarding: This occurs when two competitive males are not in the same enclosure but has visual contact.

Male-female Lateral Display: This particular behaviour was observed during the earlier stage of breeding season.

"Wing-whirring":This is a genus specific courtship behaviour of pheasants.

Courtship Feeding: During the time of feeding, male attracts female by producing noise.

Mating: The pair then chose the hiding place provided by the zoo authority for copulation.

Artificial incubation: Out of three fertilised eggs, only two hatched and grew well. The body weight of two chicks were measured and mentioned in the Graph 1 . The body weights 
of both the chicks were $24 \mathrm{~g}$ and $19 \mathrm{~g}$ respectively in day-1. But in the second week or in between day-7 to day-13, the body weights of both the chicks were unexpectedly decreased. This may be due to the consuming of the yolk content that they possessed after being hatched and simultaneously gradual increase of their daily activity. By day-14 onwards the growth rate curve of the chick gradually turned logistically upward up to day98 and the body weight of both the chicks were recorded as $203 \mathrm{~g}$ and $213 \mathrm{~g}$ respectively (Graph 1). The graph also showed that, the body weight of the first chick was more than the second chick in between day-1 to day- 20 . But from the day-21 onwards the body weight of second chick was more than first one up to day-98. After 3 months, both the chicks were transferred from brooder to the nursery of the zoo. The colouration of the plumage confirms that chick 1 is female and chick 2 is male Silver Pheasant (Fig. 3 and Fig. 4).

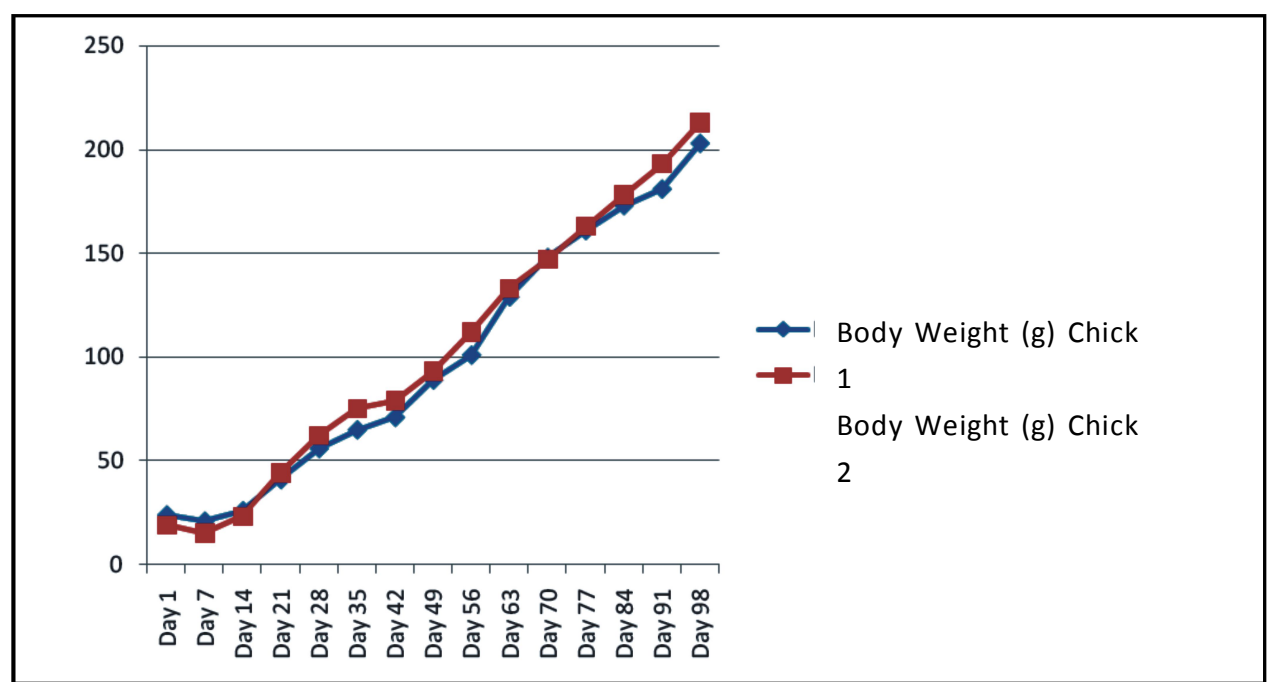

Graph 1. Showing growth rate of two chicks from day-1 to day-98

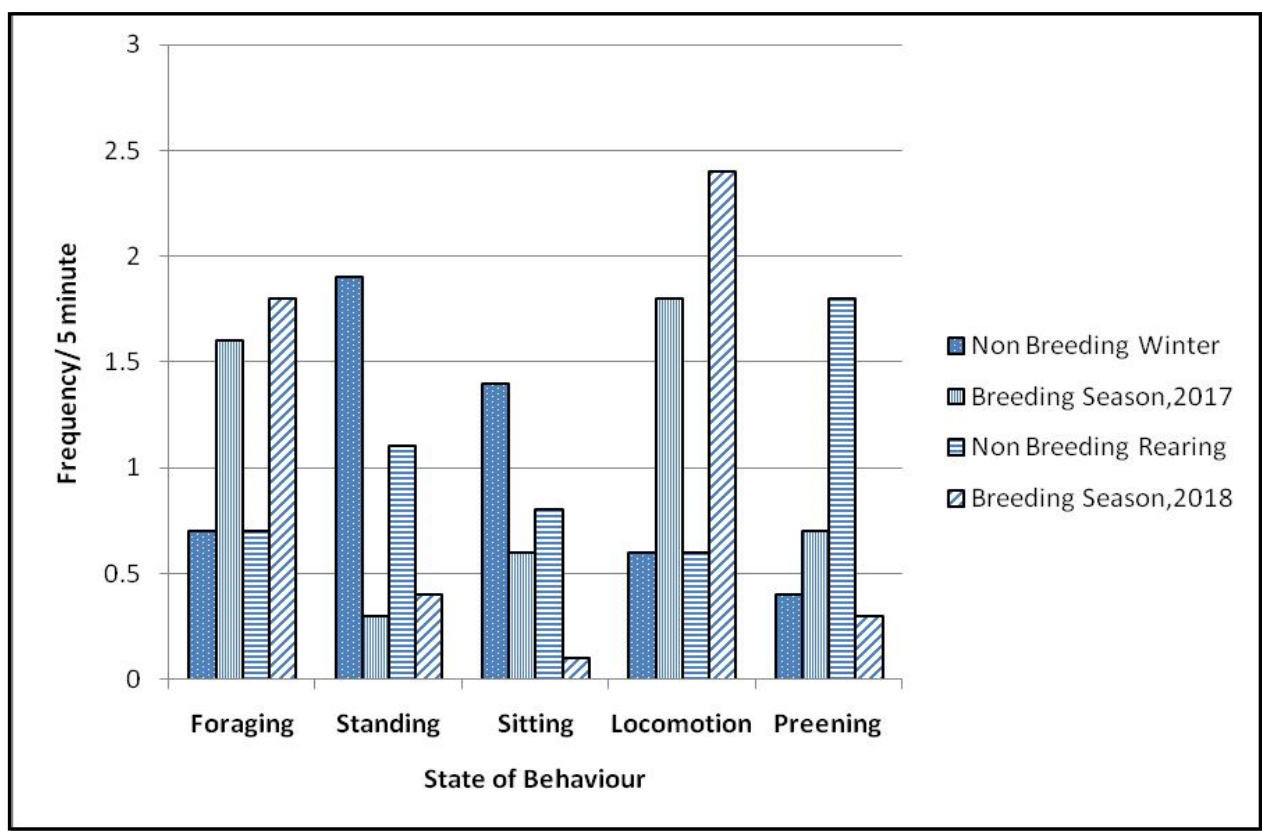

Graph 2. Showing seasonal activity budget of the birds during 2017 and 2018 
Indian Journal of Animal Health, June, 2020

Courtship behaviour and artificial breeding of Silver Pheasant

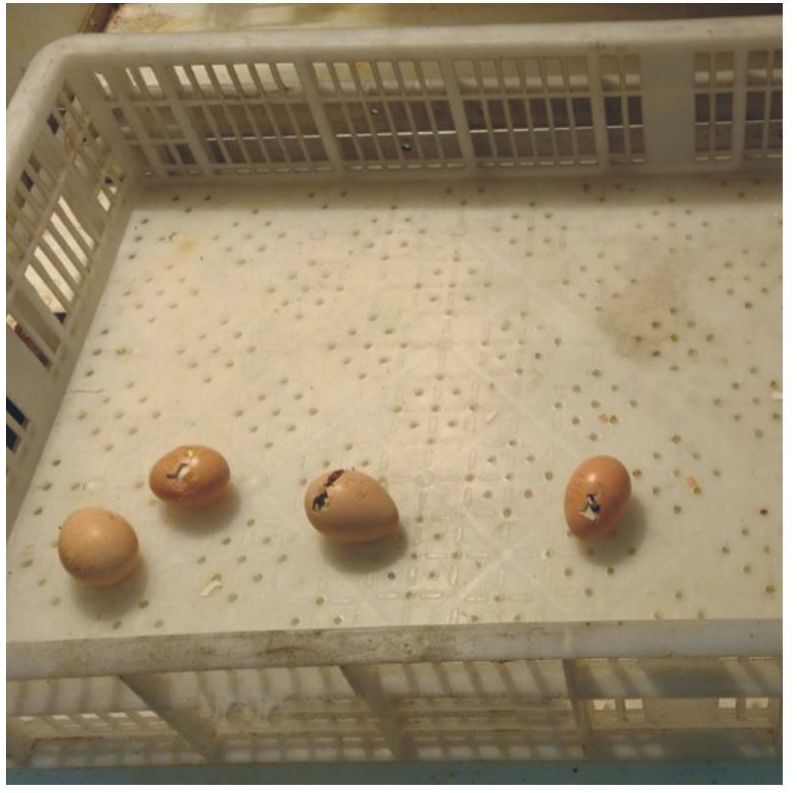

Fig. 1. Setter with Pheasant eggs

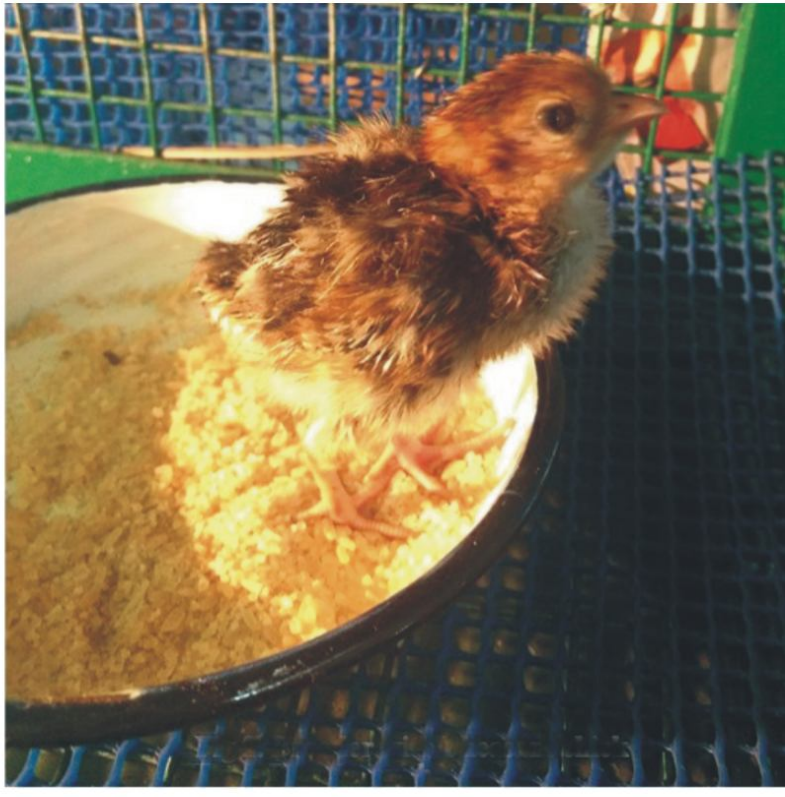

Fig. 2. Brooder with Pheasant chick

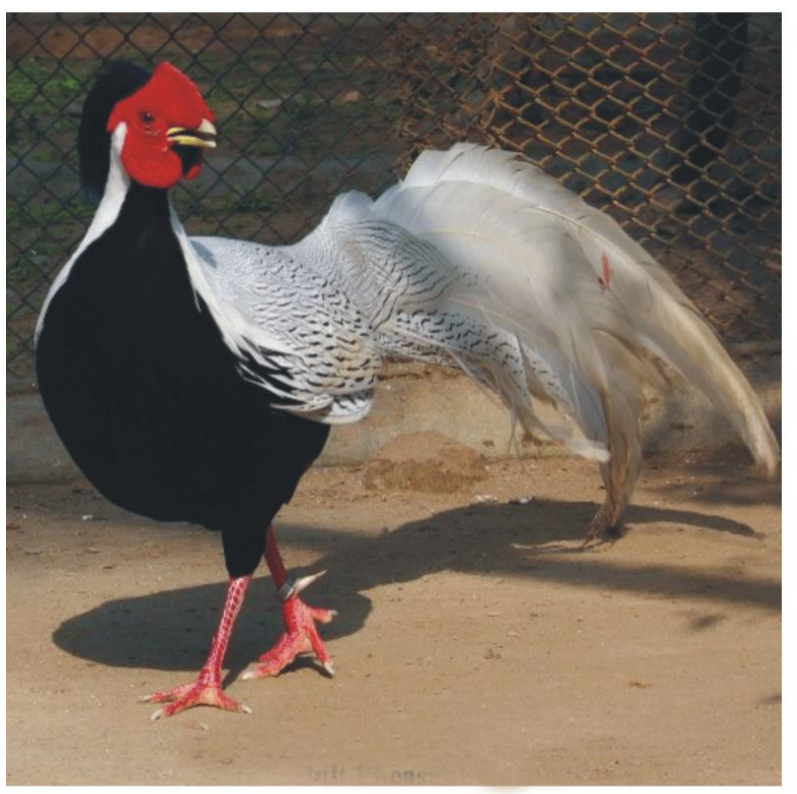

Fig. 3. Adult Pheasant (Male)

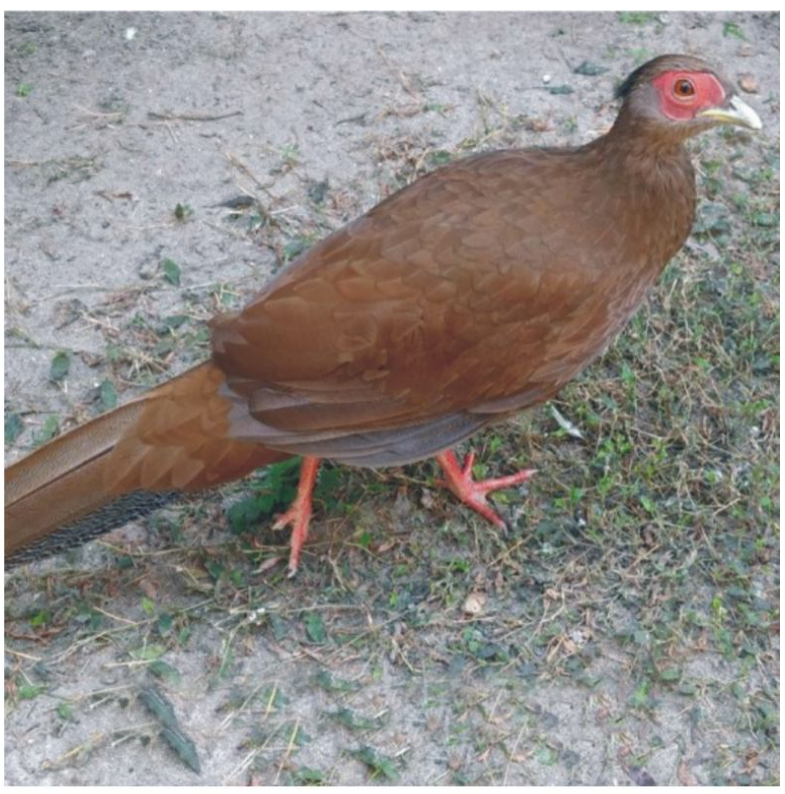

Fig. 4. Adult Pheasant (Female) 


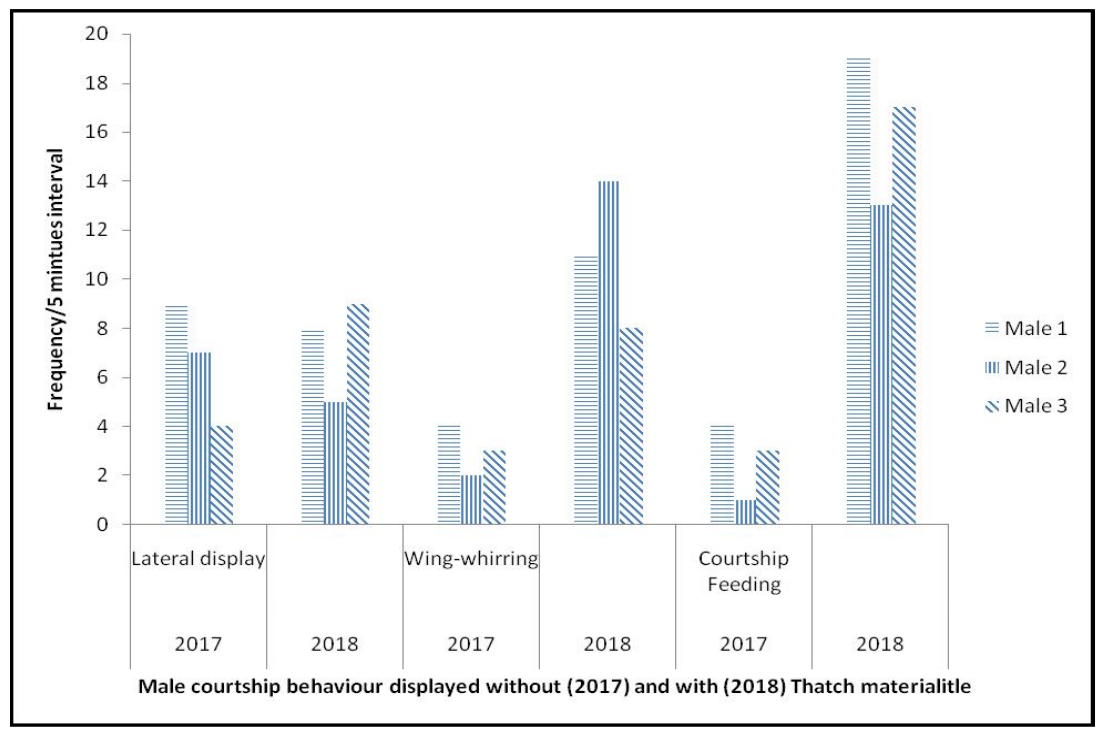

Graph 3. Showing male courtship behaviour displayed without (2017) and with (2018) Thatch material

\section{DISCUSSION}

\section{Seasonal activity budget}

During the breeding season of 2017 and 2018, the frequency of foraging and locomotion increased significantly. In contrary, during the non breeding winter, standing, sitting and preening increased significantly (Graph 2).

Mate Guarding: It was observed that male stayed close to its partner, often moving its head up and down with low drumming sound and scanning the surrounding. In the evening, the male followed his mate to the roost and perched in trees behind her. At dawn the male usually became active earlier and flew to the ground calling his mate, which still slept or preened on the perch.

Male-female Lateral Display: The male stood or walked sideways towards the female with his head lowered, facial wattles enlarged and tail fanned, giving low and continuous calls. Whereas, the females always became panicky and tried to escape.

"Wing-whirring": It was clearly observed that fast wing beats, producing vibrations and whirring noises was the typical features of wing-whirring.

Courtship Feeding: The male approached the food and dabbled a few times and began to call. When the hen came nearby, he froze over the food, if the female ate the pecked object, the male attempted to mount her and the female showed submission.

Mating: It was taken 3-5 successive mounting to complete the mating process.

Courtship behaviour displayed by the males during the year 2017 and 2018: Courtship behaviour included lateral display, wing whirring and courtship feeding. It was observed that earlier in 2017 there was non-availability of hiding place whereas in 2018 hiding place was constructed for comfortable breeding. There was no statistically significant variation observed in lateral display of 2017 and 2018. On the other hand, wing whirring and courtship feeding remarkably higher in 2018 than that of 2017. This data was statistically analysed and found significant variation in between 2017 and 2018. It was also observed from the compiled data that successful hatching was not noticed in natural way in 2017, whereas in 2018 successful natural hatching observed pronouncedly.

From the conjugated data of higher rate of wing whirring and courtship feeding with higher degree of successful natural hatching in 2018 led us to conclude, that, though the lateral display was considered as courtship behaviour by earlier researchers (Kuck, 1968), wing whirring and courtship feeding played pivotal role in successful breeding (Graph 3). 
Activity budgets changed seasonally. Though male-female lateral display was considered as a potential breeding behaviour, wing-whirring and courtship feeding were two most important behaviours regarding successful mating. Proper privacy with comfort was required for successful mating as well as brooding. The captive breeding can be considered as a tool for conservation, in addition it has educational and scientific purposes. This documentation of work is the first at Zoological Garden, Alipore, Kolkata, in respect of captive

\section{REFERENCES}

BackYardChickens.com, https://www. backyardchickens.com/articles/how-to-raise-baby chicks\%E2\%80\%94the-first-60-days-of-raisingbaby-chickens.47691/. Accessed on 22.1.20 at 22:09 pm

Balmford A, Kroshko J, Leader-Williams N and Mason G, 2011. Zoos and captive breeding. Science, 332(6034): 1149-1150, doi:10.1126/science. $332.6034 .1149-\mathrm{k}$

Banerjee GC, 1998. A Textbook of Animal Husbandry. Oxford and IBH Publishers. $8^{\text {th }}$ Edn., pp874-876

Boleli IC, Morita VS, Matos Jr JB, Thimotheo M and Almeida VR, 2016. Poultry egg incubation: Integrating and optimizing production efficiency. Brazilian J Poult Sci, 2: 001-016, http://dx.doi.org/ 10.1590/1806-9061-2016-0292

Botero CA and Rubenstein DR, 2012. Fluctuating environments, sexual selection and the evolution of flexible mate choice in birds. PLoS One, 7(2): e32311, doi:10.1371/journal.pone.0032311

Brander GC and Pugh DM, 1971. Veterinary Applied Pharmacology and Therapeutics. ELBS London, $2^{\text {nd }}$ Edn.

Comizzoli P and Holt WV, 2019. Breakthroughs and new horizons in reproductive biology of rare and endangered animal species. Biol Reprod, 101(3): 514-525, doi:10.1093/biolre/ioz 031

Croteau E and Mott CL, 2011. Saving endangered species: a case study using global amphibian declines. Nat Edu Know, 4(4): 9

Deeming DC, Hodges HR and Cooper JJ, 2011. Effect of sight barriers in pens of breeding ring-necked pheasants (Phasianus colchicus): I. Behaviour and breeding via artificial incubation technique of Silver Pheasant, which will definitely help to monitor the behavioural, veterinary and nutritional research under captive conditions over a period of time.

\section{ACKNOWLEDGEMENT}

Authors are thankful to the Member Secretary, West Bengal Zoo Authority, and all the veterinarians, staffs and animal keepers of Zoological Garden, Alipore, Kolkata for their support.

welfare. British Poul Sci, 52(4): 403-414, doi: 10.1080/00071668.2011. 590796

Heinrichs JA, McKinnon DT and Aldridge CL, 2019. Optimizing the use of endangered species in multipopulation collection, captive breeding and release programs. Glob Ecol Conserv, 17: e00558, doi:10.1016/j.gecco.2019.e00558

Hunt J, Casper J, Breuker, Jennifer A, Sadowsk I et al., 2009. Male-male competition, female mate choice and their interaction: Determining total sexual selection. J Evol Biol, 2(2): 13-26, doi:10.1111/j.1420-9101.2008.01633.x

Kuck TL, 1968. Movements and behavior of pheasants during the breeding cycle as determined by radiotracking. Electronic Theses and Dissertations, 158, https://openprairie.sdstate.edu/etd/158

Santilli F and Bagliacca M, 2017. Effect of perches on morphology, welfare and behaviour of captive reared pheasants. Italian J Anim Sci, 16:(2): 317320, doi: 10.1080/1828051X.2016.1270781

Santilli F and Bagliacca M, 2019. Fear and behavior of young pheasants reared with or without parent figure. Avian Biol Res, 12(1): 23-27, doi:10.1177/ 1758155919826765

Tan CKW, Doyle P, Bagshaw E, Richardson DS and Wigby S, 2016. The contrasting role of male relatedness in different mechanisms of sexual selection in red jungle fowl. Evolution, 71(2): 403-420, doi:10.1111/evo.13145

Tollefson J, 2019. Humans are driving one million species to extinction. Landmark United Nationsbacked report finds that agriculture is one of the biggest threats to Earth's ecosystems. Nature, 569: 171, doi: 10.1038/d41586-019-01448-4

Received-12.02.2020, Accepted-28.04.2020, Published-01.06.2020 